\title{
A MULTIPLE ELECTRODE CARRIER FOR CHRONIC IMPLANTATION IN SMALL ANIMALS 1
}

\author{
Thomas Law, Ph.D. and H. William Wise \\ Mental Health Research Institute, University of Michigan, \\ Ann Arbor, Mich.
}

(Received for publication: March 10, 1958)

Since its introduction by Hess (1932), the chronic indwelling electrode has become a major tool for the study of the central nervous system. A variety of modifications have been introduced to permit the use of multiple electrode leads in a single assembly (Burlo 1955; Delgado, Hamlin, and Chapman 1952). The technique has been extended from the earlier work on cats to methods useful in the dog (Hume and Ganong 1956), monkey (Delgado 1955), and even the human (Becker et al. 1957).

Requirements such as rigidity of the carrier assembly, size of the mounting screws which secure it to the skull, and limitations set by the size of a bundle of many electrodes, have hindered the extension of the technique to small animals. Olds and Milner (1954) have reported a method for the implantation of one pair of electrodes in the brain of the rat. Although their method works well, each electrode pair requires a separate carrier assembly.

This report describes a method for implantation of multiple electrodes in small animals. The design to be described is an acrylic plastic (Lucite) assembly which provides contact between small flexible insulated electrodes and rigid external lead wires. The lead wires make contact by threading through the plastic until they crush the intracranial electrodes. No soldering or seraping of insulation is involved. The teehnique is applicable to rats, hamsters, guinea pigs, squirrels, ete. Application to larger animals is easy.

The model discussed in this article is intended for 4 electrodes. Actual use has shown the practicality of as many as 12 electrodes.

Figure 1 shows the various parts. The stainless steel rods at A are 0.0359 "dental wire, crimped at the upper end and threaded with 0.038 " -140 jeweler's dies. Holes are edge-drilled somewhat smaller (0.031") in the vertical plastic piece $B$ to accommodate the threaded rods. In practice it has been found that tapping the plastic to receive the thread on the vertical rods is unnecessary. The normal resiliency of the plastic and the hardness of the stainless steel rods

1 The work reported in this paper was supported by United States Public Health Service Grant No. M-1379. Th support and encouragement of Professor $R$. $W$. Gerard is gratefully acknowledged. permits the latter to thread their own course. A second set of holes is drilled near the lower edge in the face of part $B$ at right angles to, and intersecting with, the first set. As illustrated at $\mathrm{C}$, this second set is intended for the electrode wires.

At $D$ the base plate is shown from above, with its set of 4 stainless serews $\left(0.0315^{\prime \prime}-128\right)$ used to secure it to the skull. The plate is cemented to the vertical piece. Parts $A, B$, and $D$ are shown assembled at C. Ethylene dichloride, or one of the commercial acrylic cements, makes a rigid bond at this joint.

F of figure 1 is the key wrench used for threading the rods in A down through the vertical piece at $B$, and for tightening them on the electrode wire. It is formed from a length of hypodermic needle tubing, one end of which is crimped to fit the crimps on the rods.

Finally, $F$ in figure 1 is the connector which makes contact between the carrier assembly and the stimulating or recording system. The connector is a duplicate of the vertical part, B. Short stainless steel lengths of wire are secured to the face of the block by machine screws, which also provide a point of contact with the wires of the cable, and then formed to protrude into the small holes at the lower end of the block. By spring action, these formed wires make contact with the rods when the contactor is slipped over them. This friction contact is adequate to hold the two together for most purposes, but when considerable movement of the animal is likely, cellulose tape can be wrapped around the whole assembly for additional security.

In use, the carrier assembly can be attached virtually anywhere on the skull surface. Burr holes for the machine screws can be made, with the assembly in position, with a $0.028^{\prime \prime}$ drill held in a pin vise. No tapping of the skull is necessary. The electrodes (Teflon-insulated 40 gauge stainless steel) are brought to the skull surface at any remote point, bent to run parallel to the skull, and fed through the holes, as in $\mathrm{C}$ of figure 1 . The excess protruding from the other side is clipped off. The threaded rods are then screwed down onto the electrodes. The insulation is 
scraped from the electrode as the rod is screwed down into it. Excellent mechanical security and electrical contact are provided at the same time. No soldering is necessary at any point in the system. Finally, dental cement is spread around the base of the assembly to seal off the protruding cut ends of the electrodes, and the scalp is closed.

This method leaves the vertical rods for external contact exposed and unprotected when not in use. This disadvantage is easily overeome by fitting over together, or by using round plastic rod instead, with concentric rings of staggered holes.

Experience with the present method shows that 4 or more electrodes may easily be implanted in a rat in less than 1 hour. Sterilization of the assembly is by immersion in Zephiran solution (1:1000) for 24 hours.

The advantages of the technique deseribed are:

1. The use of large numbers of electrodes with a small electrode carrier, appropriate to the dimensions of small animals such as the rat.

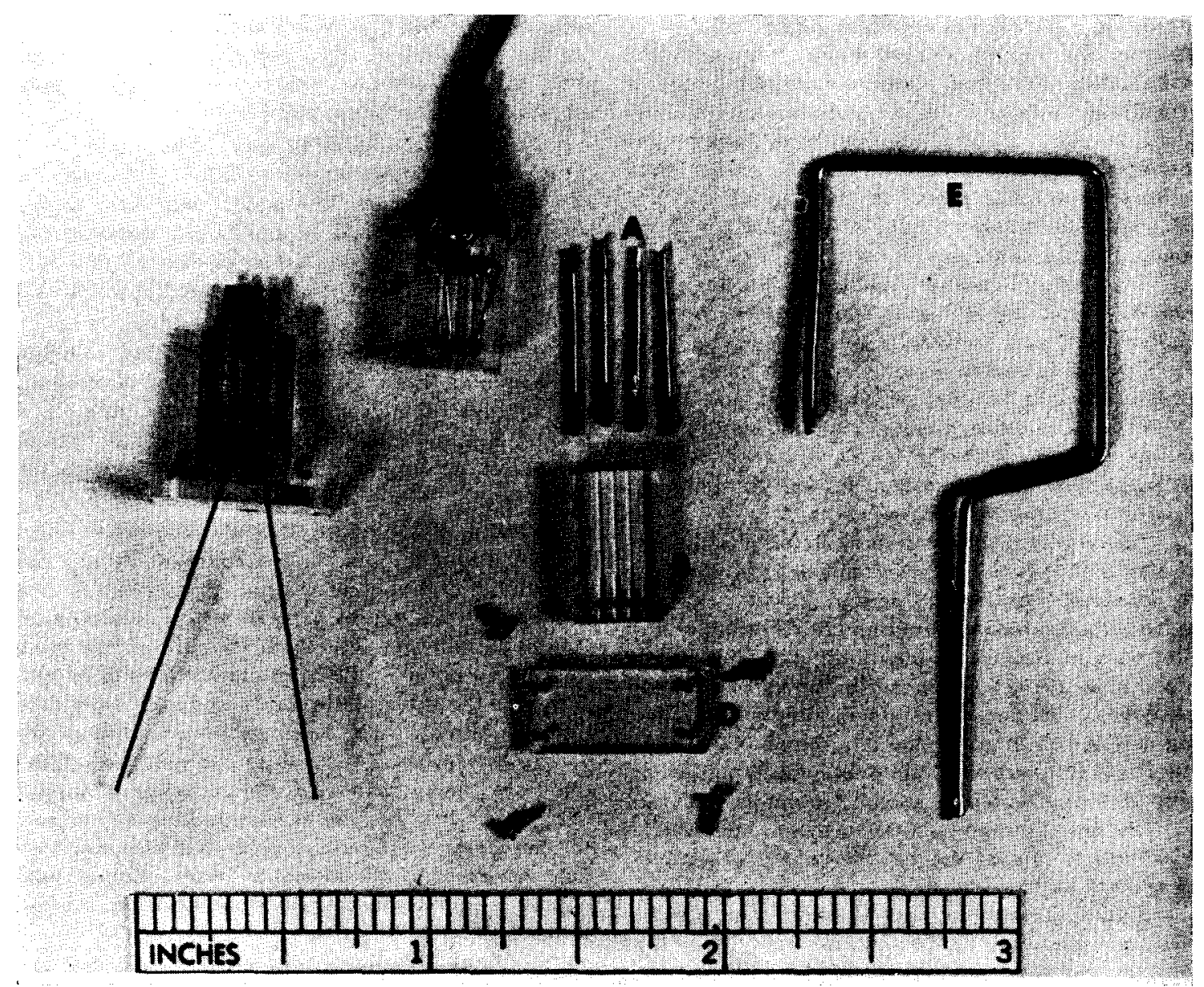

Fig. 1

them a protective cap similar to the connector ( $F$ in figure 1) and securing it with cellulose tape.

The present example illustrates the 4 electrode carrier, since this is the usual requirement for bilateral stimulation. Larger arrays can easily be accommodated by increasing the thickness of the vertical piece to permit the rods to be staggered and placed closer
2. Rapidity and ease of installation.

3. Reliability of contact between implanted electrode and external connections.

4. The use of durable external contacts with small intracranial leads.

5. The elimination of solder contacts.

6. Simplicity and economy of construction. 


\section{REFERENCES}

Becker, H. C., Founds, W. L., Peacock, JR., S. M. Heath, R. G., Llewellyn, R. C, and Mickle, W. A. A roentgenographic stereotaxic technique for implanting and maintaining electrodes in the brain of man. EEG Clin. Neurophysiol., 1957, $9: 533-543$.

Burlo, J. M. A multiple electrode for depth recording. EEG Clin. Neurophysiol., 1955, $7: 655$.

Delgado, J. M. R. Evaluation of permanent implantation of electrodes within the brain. EEG Clin. Neurophysiol., 1955, 7 : 637-644.

Delgado, J. M. R., Hamlin, H. and Chapman, W. Technique of intraeranial electrode implacement for recording and stimulation and its possible therapeutic value in psychotic patients. Conf. Neurol., 1952, 12: 315-319.

Hess, W. R. Beitrage zur Physiologie d. Hirnstam. mes I. Die Methodik der lokalisierten Reizung und A usschaltung subkortikaler Hirnabschnitte. Leipzig, Georg Thième, 1932, 122 pp.

Hume, D. M. and Ganong, W. F. A method for accurate placement of electrodes in the hypothal. amus of the dog. EEG Clin. Neurophysiol., 1956, $8: 136-140$.

Olds, J. and Mrlner, P. Positive reinforeement produced by electrical stimulation of septal area and other regions of rat brain. J. Comp. Physiol. Psychol., 1954, 47: 419-427. Reference: LAW, T. and Wise, H. W. A multiple electrode carrier for chronic implantation in small ani-
mals. EEG Clin. Neurophysiol., 1958, 10: 749-751. 